\title{
Análises físico-química de fórmulas infantis à base de aminoácidos livres utilizadas no tratamento da alergia à proteína do leite de vaca
}

\author{
Physicochemical analysis of free amino acid-based infant formula used in the treatment of cow's
} milk protein allergy

Análisis fisicoquímicos de fórmulas infantiles a base de aminoácidos libres utilizadas en el tratamiento de la alergia a las proteínas de la leche de vaca

João Marcos Luz Sousa Barros ORCID: https://orcid.org/0000-0003-4862-1845 Centro Universitário Unifacid Wyden, Brasil E-mail: joaomarcoslsb@gmail.com

Alice Lima Rosa Mendes ORCID: https://orcid.org/0000-0002-1960-9647 Universidade de Brasília, Brasil E-mail: alice_lima_@hotmail.com Suely Moura Melo

ORCID: https://orcid.org/0000-0001-9996-0850 Centro Universitário Unifacid Wyden, Brasil E-mail: suelymouramelo@yahoo.com.br

\begin{abstract}
Resumo
A alergia à proteína do leite de vaca é uma doença inflamatória, imunologicamente mediada, que acomete principalmente o trato gastrintestinal e a pele. O objetivo geral da pesquisa é analisar o perfil de qualidade de fórmulas infantis à base de aminoácidos livres utilizando métodos físico-químicos. Trata-se de uma pesquisa do tipo explicativa, de método experimental com abordagem qualitativa e quantitativa, no qual foram analisadas duas marcas de fórmula infantil à base de aminoácidos Livres. As amostras foram preparadas de acordo com o estabelecido pelo fabricante. Os métodos físico-químicos utilizados foram, prova de reconstituição/estabilidade, teste visual de cor e análise de potencial hidrogeniônico. No teste de reconstituição/estabilidade das fórmulas, as duas marcas apresentaram estáveis após o preparo, nos dois tipos de água “água filtrada/fervida e água mineral” e nos tempos estipulados. No teste de cor, as duas marcas apresentaram a coloração branco/amarelado após o preparo, nos dois tipos de água e em todos os tempos estipulados. $\mathrm{Na}$ análise de potencial hidrogeniônico, houve uma diferença entre as duas fórmulas analisadas. A Fórmula 1 apresentou-se mais ácida e a Fórmula 2, mais alcalina. Além disso, no decorrer do tempo houve uma pequena redução nos valores de $\mathrm{pH}$ em ambas as fórmulas e nos dois tipos de água. Conclui-se que foi possível realizar todas as análises dos parâmetros físico-químicos e que as duas Fórmulas infantis à base de aminoácidos livres só apresentaram pequenas variações no quesito de potencial hidrogeniônico. No entanto, é necessário a realização demais testes físico-químicos para garantir a qualidade dos produtos analisados.
\end{abstract}

Palavras-chave: Alergia à proteína do leite de vaca; Fórmulas infantis; Análise físico-química.

\begin{abstract}
Allergy to cow's milk protein is an inflammatory, immunologically mediated disease that mainly affects the gastrointestinal tract and the skin. The general objective of the research is to analyze the quality profile of infant formulas based on free amino acids using physicochemical methods. This is an explanatory research, using an experimental method with a qualitative and quantitative approach, in which two brands of infant formula based on Free amino acids were analyzed. The samples were prepared as established by the manufacturer. The physicochemical methods used were, reconstitution/stability test, visual color test and hydrogen ionic potential analysis. In the reconstitution/stability test of the formulas, the two brands were stable after preparation, in the two types of water "filtered/boiled water and mineral water" and within the stipulated times. In the color test, the two brands showed a white/yellowish color after preparation, in both types of water and at all stipulated times. In the analysis of hydrogenionic potential, there was a difference between the two analyzed formulas. Formula 1 was more acidic and Formula 2 was more alkaline. Furthermore, over time there was a small reduction in $\mathrm{pH}$ values in both formulas and in both types of water. It was concluded that it was possible to carry out all the analyzes of the physicochemical parameters and that the two Infant Formulas based on free amino acids only presented small variations in the item of hydrogenionic potential. However, it is necessary to carry out other physical-chemical tests to guarantee the quality of the analyzed products.
\end{abstract}

Keywords: Allergy to cow's milk protein; Infant fórmulas; Chemical physical analysis. 


\section{Resumen}

La alergia a la proteína de la leche de vaca es una enfermedad inflamatoria mediada inmunológicamente que afecta principalmente al tracto gastrointestinal y la piel. El objetivo general de la investigación es analizar el perfil de calidad de las fórmulas infantiles basadas en aminoácidos libres mediante métodos fisicoquímicos. Se trata de una investigación explicativa, utilizando un método experimental con enfoque cualitativo y cuantitativo, en el que se analizaron dos marcas de fórmula infantil a base de aminoácidos libres. Las muestras se prepararon según lo establecido por el fabricante. Los métodos fisicoquímicos utilizados fueron, prueba de reconstitución / estabilidad, prueba de color visual y análisis de potencial iónico de hidrógeno. En la prueba de reconstitución / estabilidad de las fórmulas, las dos marcas se mantuvieron estables después de su preparación, en los dos tipos de agua "agua filtrada / hervida y agua mineral" y dentro de los tiempos estipulados. En la prueba de color, las dos marcas mostraron un color blanco / amarillento después de la preparación, en ambos tipos de agua y en todos los tiempos estipulados. En el análisis de potencial hidrogeniónico, hubo diferencia entre las dos fórmulas analizadas. La Fórmula 1 fue más ácida y la Fórmula 2 fue más alcalina. Además, con el tiempo se produjo una pequeña reducción de los valores de $\mathrm{pH}$ en ambas fórmulas y en ambos tipos de agua. Se concluyó que fue posible realizar todos los análisis de los parámetros fisicoquímicos y que las dos fórmulas infantiles basadas en aminoácidos libres solo presentaban pequeñas variaciones en el ítem de potencial hidroiónico. Sin embargo, es necesario realizar otras pruebas físico-químicas para garantizar la calidad de los productos analizados.

Palabras clave: Alergia a la proteína de la leche de vaca; Fórmulas para lactantes; Análisis físico-químico.

\section{Introduçãa}

A alergia alimentar constituiu um importante problema de saúde pública e é definida como um efeito adverso resultante de uma resposta imunológica específica que ocorre de forma repetível após exposição a um dado alimento (Ferreira et al., 2014).

As fórmulas nutricionais utilizadas na Alergia à Proteína do Leite de Vaca (APLV) são as fórmulas à base de soja, à base de proteína extensamente hidrolisada e à base de aminoácidos. A indicação do uso de fórmulas infantis para APLV deve ocorrer para substituição da alimentação em crianças menores de seis meses ou complementação para maiores de seis meses. (Brasil, 2018).

As fórmulas infantis à base de aminoácidos livres são importante fonte alimentar de crianças lactentes ou de primeira infância alérgicas à proteína do leite de vaca (Tavares, 2013). Em vista disso, o problema de pesquisa é: por quanto tempo, após o preparo, as fórmulas infantis à base de aminoácidos livres podem ser consumidas por lactentes e crianças de primeira infância? O tipo de água influencia no preparo dessas fórmulas?

Portanto, a pesquisa irá identificar e avaliar as alterações físico-químicas que as fórmulas infantis à base de aminoácidos livres podem sofrer durante e após o preparo, garantindo segurança para alimentação da criança. Baseado nisso, o objetivo geral da pesquisa é analisar o perfil de qualidade de fórmulas infantis à base de aminoácidos livres utilizando métodos físico-químicos.

\section{Metodologia}

Diante disso, trata-se de uma pesquisa do tipo explicativa, de método experimental com abordagem quali-quantitativa que foram analisadas duas marcas de Fórmulas Infantis à Base de Aminoácidos Livres. As etapas do método foram realizadas no Laboratório Multidisciplinar localizado no Centro Universitário - UNIFACID, Teresina-Piauí, Brasil.

As amostras de Fórmula Infantil à Base de Aminoácidos Livres e a água mineral foram adquiridas em estabelecimentos comerciais localizados em Teresina-PI. A água filtrada foi coletada em um filtro residencial com manutenção recente. As amostras foram preparadas de acordo com o estabelecido pelo fabricante. As amostras foram preparadas para um volume de 100 $\mathrm{ml}$, em triplicata. Sendo divididas em fórmula A e fórmula B.

A fórmula A, foi em um Em um béquer de $200 \mathrm{~mL}$, ferveu-se de água filtrada por $5 \mathrm{~min}$, em seguida deixou esfriando até a temperatura $40{ }^{\circ} \mathrm{C}$, então foram retiradas $90 \mathrm{~mL}$ de água e adicionou-se 3 colheres da medida disponibilizada pelo fabricante (13,8 g) (Figura1). Agitou-se, com auxílio de um bastão de vidro, até a completa dissolução do pó. 
Figura 1 - Colher medida disponibilizada pelo fabricante da Fórmula A.

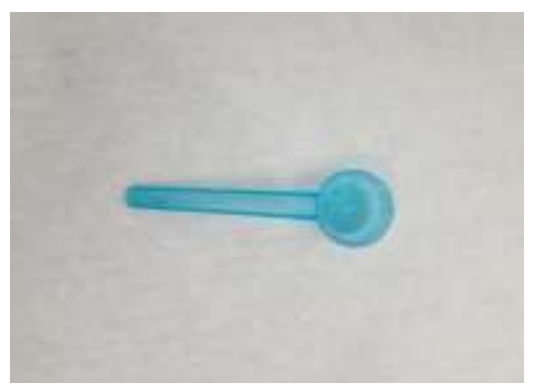

Fonte: Dados da pesquisa (2021).

Em um béquer ferveu-se a fórmula $\mathrm{B}$ com à água filtrada por 5 minutos. Em seguida, deixou-se esfriar até obter temperatura ambiente. Adicionou-se 1 colher medida, $25 \mathrm{~g}$, disponibilizada pelo fabricante (Figura 2), em $85 \mathrm{ml}$ de água em outro béquer. Agitou-se, com auxílio de um bastão de vidro, até a completa dissolução do pó. Em outro béquer adicionou-se 85 $\mathrm{ml}$ de água mineral, em temperatura ambiente, e 1 colher medida, $25 \mathrm{~g}$, disponibilizada pelo fabricante. Agitou-se, com auxílio de um bastão de vidro, até a completa dissolução do pó.

Figura 2 - Colher medida disponibilizada pelo fabricante da Fórmula B.

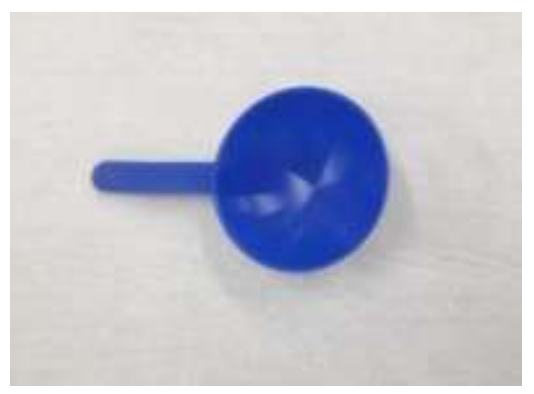

Fonte: Dados da pesquisa (2021).

Após o preparo, foi realizado a prova de reconstituição/estabilidade das amostras e foram colocadas em uma geladeira e foram observadas nos tempos de 30, 120 minutos e 24 horas, com o intuito de verificar se elas mantêm como fluidas, isto é, estável sem precipitação. Após esse experimento foi realizado o teste de cor que foi observado a coloração das amostras pelo método visual. O teste de $\mathrm{pH}$ foi realizado com o auxílio do pHmetro, previamente calibrado, foi medido o $\mathrm{pH}$ de cada amostra. A organização e análise de dados sofreram ordenação de tratamento estatístico descritivo, com determinação da média e desvio padrão utilizando o programa Microsoft Office Excel® 2019.

\section{Resultados e Discussão}

De acordo com a RDC n 48 de 2014, as fórmulas infantis à base de aminoácidos livres devem ser preparadas com água fervida e posteriormente resfriada. Além disso, essas fórmulas devem ser consumidas imediatamente após a reconstituição e quando necessário o preparo com antecedência do produto, a fórmula reconstituída deve ser refrigerada à temperatura menor que $5^{\circ} \mathrm{C}$, por no máximo 24 horas.

Em relação à reconstituição das fórmulas, as duas marcas de Fórmula infantil à base de aminoácidos livres mostraramse estável, sem a presença de precipitados, em todos os tempos estipulados e nos dois tipos de água.

A RDC n48 de 2014 preconiza que quando as fórmulas sejam preparadas de acordo com as instruções do rótulo, os produtos devem estar livres de grumos e partículas grossas. As duas fórmulas apresentaram-se uniformes, líquidas e sem nenhuma presença de partículas visíveis a olho nu. 
Para a reconstituição de fórmulas infantis, um fator essencial é a qualidade da água utilizada, recomendando-se que esta seja fervida e posteriormente resfriada (Rodrigues et al., 2019). No entanto, a água mineral não sofreu o processo de fervura e foi utilizada em temperatura ambiente, portanto, a etapa de fervura nas condições experimentais não influenciou na reconstituição das duas fórmulas.

A razão para a água ser resfriada ou utilizada em temperatura ambiente está relacionado com diversos aspectos como as perdas de alguns nutrientes termossensíveis. Um aspecto bastante importante são as perdas de alguns nutrientes termossensíveis. Um estudo realizado pela (FAO/WHO 2006) verificou-se que ocorria uma redução entre 5,6 e 65,6\% nos níveis de vitamina $\mathrm{C}$ quando a fórmula é reconstituída com água fervente. Outro aspecto considerável é que em algumas fórmulas, a presença de aglomeração de pó pode ocorrer após a reconstituição com água quente. Além disso, a água quente pode ativar alguns esporos e bactérias presentes eventualmente nas fórmulas. Vale ressaltar, também, a possibilidade de acidentes com a utilização de água a temperaturas elevadas, como queimaduras, nas crianças que recebem essa alimentação e/ou nos preparadores (Assunção, 2008).

A análise sensorial é uma ciência que avalia as características organolépticas dos alimentos através das percepções identificadas pelos sentidos humanos, aplicada de maneira inconsciente, no momento que estes julgam e decidem sobre suas preferências (Segalla et al., 2015).

Em relação ao teste visual de cor, foi possível observar que não teve nenhuma alteração de cor após o preparo das duas marcas de Fórmula infantil à base de aminoácidos livres. O tipo de água não influenciou na coloração das fórmulas. Sendo assim, todas as amostras permaneceram com uma coloração branco/amarelado, mesmo depois de 24 horas.

A Figura 3 representa a cor obtida pela Fórmula 1 preparadas com os dois tipos de água após 24 horas. A Figura 4 demonstra a cor obtida pela Fórmula 2.

Figura 3 - Cor obtida pela Fórmula 1 após 24 horas de preparo.

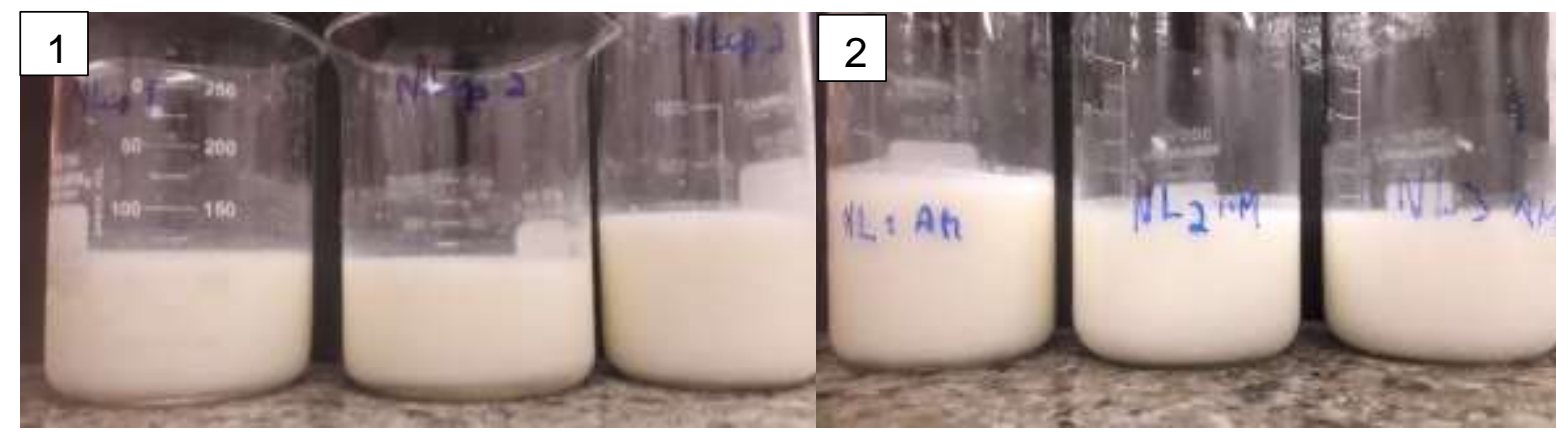

Legenda: Leite com amostra: 1 - C/ Água filtrada; 2 - C/ Água mineral; -3 C/ Água fervida. Fonte: Dados da pesquisa (2021).

Figura 4 - Cor obtida pela Fórmula 2 após 24 horas de preparo.

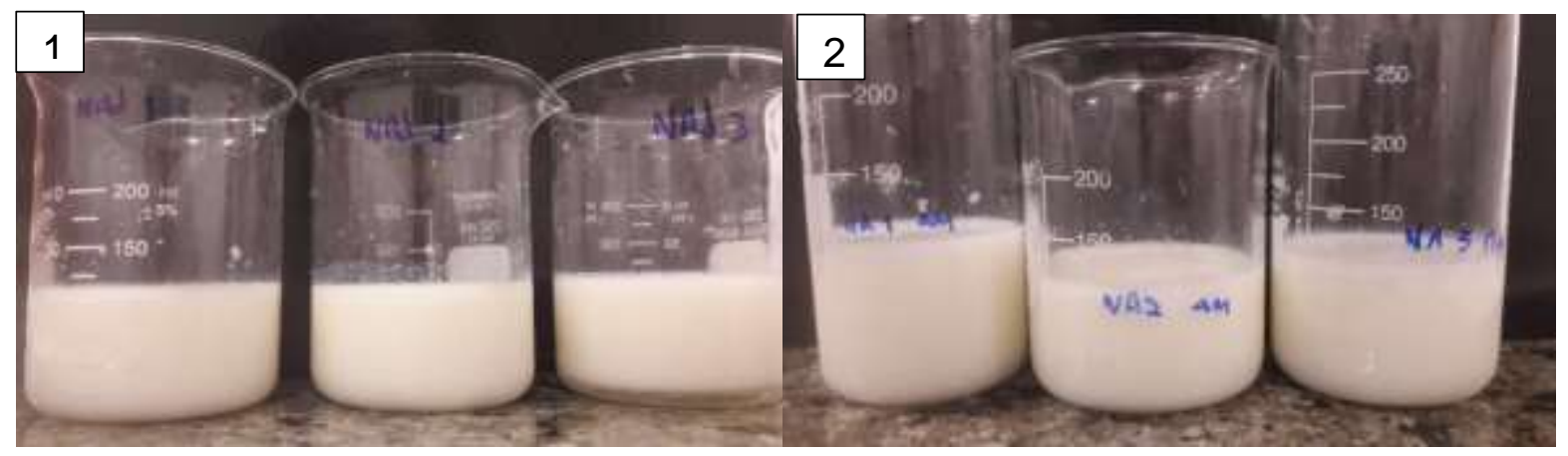

Legenda: Leite com amostra: 1 - C/ Água filtrada; 2 - C/ Água mineral 3 C/ Água fervida. Fonte: Dados da pesquisa (2021). 
A análise visual de cor foi realizada objetivando-se verificar possíveis mudanças após o preparo das fórmulas. A cor é a primeira indicação da qualidade de um produto e deve-se pela presença de pigmentos naturais. Estes pigmentos são instáveis, participam de diferentes reações e, em função disto, a alteração de cor é um indicador das alterações químicas e bioquímicas possíveis de ocorrer durante o preparo e estocagem (Ribeiro et al., 2007).

Além disso, os microrganismos, também, são causadores de alterações químicas prejudiciais, resultando em deterioração microbiana, que muitas vezes resulta em alterações de cor em alimentos. Estas mudanças são consequência da atividade metabólica dos microrganismos que utilizam o alimento como fonte de energia (Franco \& Landgraf, 2008).

É válido ressaltar que essas fórmulas são utilizadas em substituição ao leite materno. Comparando as fórmulas com o leite materno, é evidente que a coloração é bastante similar, pois as duas marcas obtiveram uma coloração branco/amarelado. De acordo com o que é estabelecido pela Agência Nacional de Vigilância Sanitária (ANVISA) (2008) no material Banco de Leite Humano, o leite materno pode apresentar três variações de cor, dependendo do momento da ordenha. No início o leite pode apresentar uma coloração que lembra "água de coco”, na fase intermediária uma cor que tende para o branco-opaco e no estágio final uma coloração mais amarelada.

A determinação do $\mathrm{pH}$ é importante para as determinações de deterioração do alimento com o crescimento de microrganismos, atividade das enzimas, retenção de sabor e odor de produtos, portanto, bastante utilizado para o controle de qualidade de produtos lácteos (Britto, 2014). A Tabela 1 representa os valores de pH obtidos após o preparo da Fórmula 1 com água filtrada e água mineral, no decorrer dos tempos estipulados.

Tabela 1 - Valores de pH da Fórmula Infantil à base de aminoácidos livres 1 com o decorrer do tempo, preparadas em dois tipos de água.

pH da Fórmula infantil à base de aminoácidos livre 1

\begin{tabular}{l|c|c}
\hline TEMPO & Água Filtrada & Água Mineral \\
\hline Após o preparo & $6,52 \pm 0,01$ & $6,53 \pm 0,02$ \\
\hline $\mathbf{3 0}$ min & $6,52 \pm 0,02$ & $6,53 \pm 0,02$ \\
\hline $\mathbf{1 2 0}$ min & $6,49 \pm 0,01$ & $6,48 \pm 0,03$ \\
\hline $\mathbf{2 4}$ hrs & $6,45 \pm 0,02$ & $6,39 \pm 0,03$ \\
\hline
\end{tabular}

Fonte: Dados da pesquisa (2021).

Antes do preparo das amostras foi verificado o $\mathrm{pH}$ dos dois tipos de água. A água filtrada obteve pH 7,34 e a água mineral, 5,35. A Fórmula 1 após o preparo com água filtrada previamente fervida, apresentou pH de 6,52, considerado levemente ácido. Após 30 minutos, o pH foi de 6,52, não apresentando diferença do pH após o preparo. Depois de 120 minutos, o valor do $\mathrm{pH}$ teve um pequeno decréscimo ficando em 6,49. Depois de 24 horas, novamente houve um decréscimo no valor do $\mathrm{pH}$, apresentando 6,45 .

A Fórmula 1 após o preparo com água mineral, obteve pH 6,53, também considerado levemente ácido. 30 min após o preparo, verificou-se que o pH se manteve em 6,53. Depois de $120 \mathrm{~min}$, houve um pequeno decréscimo, apresentando um valor de 6,48. Após 24 horas, mais uma vez houve uma redução no valor do pH, indicando 6,39. Portanto, não houve uma alteração significativa no pH no decorrer do tempo e nem diferença na utilização da água.

A Tabela 4 representa os valores de $\mathrm{pH}$ obtidos após o preparo da Fórmula 2 com água filtrada e água mineral, no decorrer dos tempos estipulados. 
Tabela 4 - Valores de pH da Fórmula Infantil à base de aminoácidos livres 2 com o decorrer do tempo, preparadas em dois tipos de água.

\section{pH da Fórmula infantil à base de aminoácidos livre 2}

\begin{tabular}{l|c|c}
\hline TEMPO & Água Filtrada & Água Mineral \\
\hline Após o preparo & $8,10 \pm 0,03$ & $8,05 \pm 0,04$ \\
\hline $\mathbf{3 0}$ min & $8,10 \pm 0,02$ & $8,05 \pm 0,05$ \\
\hline $\mathbf{1 2 0}$ min & $8,07 \pm 0,01$ & $7,94 \pm 0,05$ \\
\hline $\mathbf{2 4}$ hrs & $7,82 \pm 0,02$ & $6,67 \pm 0,02$ \\
\hline
\end{tabular}

Fonte: Dados da pesquisa (2021).

A Fórmula 2 após o preparo com água filtrada previamente fervida, apresentou $\mathrm{pH}$ de 8,10, considerado levemente alcalino. Após 30 minutos, o pH foi de 8,10, não apresentando diferença do pH após o preparo. Depois de 120 minutos, o valor do pH teve uma pequena redução ficando em 8,07. Depois de 24 horas, novamente houve redução no valor do pH, apresentando 7,82 .

Comparando os resultados obtidos no preparo da Fórmula 1 e Fórmula 2, pode-se observar que há uma diferença de pH. A Fórmula 1, apresentou-se ácida, nos dois tipos de água. Já a Fórmula 2, apresentou-se alcalina. Essa variação de pH ainda é desconhecida. Entretanto, as duas fórmulas possuem um viés, a Fórmula 1 é indicada para lactentes com idade menor ou igual a 6 meses e a Fórmula 2 é indicada para lactentes que tem idade maior que 6 meses até 1 ano de idade. Analisando a quadro nutricional das duas fórmulas, observou-se que a Fórmula 1 apresenta mais componentes nutricionais do que a Fórmula 2, como pode ser observado no Tabelas 5 e 6.

Tabela 5 - Tabela nutricional da Fórmula 1.

\begin{tabular}{|c|c|c|}
\hline \multicolumn{3}{|l|}{ Informação Nutricional } \\
\hline & Quantidade em $100 \mathrm{~g}$ de pó & Quantidade em 100ml \\
\hline Valor Energético & $483 \mathrm{kcal}=220 \mathrm{~kJ}$ & $67 \mathrm{kcal}=279 \mathrm{~kJ}$ \\
\hline Carboidratos dos quais: & $52 \mathrm{~g}$ & $7,2 \mathrm{~g}$ \\
\hline Lactose & $0 g$ & $0 \mathrm{~g}$ \\
\hline Proteínas* & $14 \mathrm{~g}$ & $1,9 \mathrm{~g}$ \\
\hline Gorduras Totais das quais: & $25 \mathrm{~g}$ & $3,4 \mathrm{~g}$ \\
\hline Gorduras Saturadas & $10 \mathrm{~g}$ & $1,4 \mathrm{~g}$ \\
\hline Gorduras Trans & $0 \mathrm{~g}$ & $0 \mathrm{~g}$ \\
\hline Ácido linoleico & $3565 \mathrm{mg}$ & $492 \mathrm{mg}$ \\
\hline Ácido alfa-linolênico & $441 \mathrm{mg}$ & $61 \mathrm{mg}$ \\
\hline Ácido docosahexaenóico (DHA) & $86 \mathrm{mg}$ & $12 \mathrm{mg}$ \\
\hline Ácido araquidônico (ARA) & $86 \mathrm{mg}$ & $12 \mathrm{mg}$ \\
\hline Fibra Alimentar & $0 g$ & $0 \mathrm{~g}$ \\
\hline Sódio & $189 \mathrm{mg}$ & $26 \mathrm{mg}$ \\
\hline Cálcio & $561 \mathrm{mg}$ & $77 \mathrm{mg}$ \\
\hline Ferro & $6,2 \mathrm{mg}$ & $0,86 \mathrm{mg}$ \\
\hline Potássio & $525 \mathrm{mg}$ & $73 \mathrm{mg}$ \\
\hline
\end{tabular}


Research, Society and Development, v. 10, n. 11, e570101119470, 2021

(CC BY 4.0) | ISSN 2525-3409 | DOI: http://dx.doi.org/10.33448/rsd-v10i11.19470

\begin{tabular}{|c|c|c|}
\hline Cloro & $386 \mathrm{mg}$ & $53 \mathrm{mg}$ \\
\hline Fósforo & $397 \mathrm{mg}$ & $55 \mathrm{mg}$ \\
\hline Magnésio & $51 \mathrm{mg}$ & $7,0 \mathrm{mg}$ \\
\hline Zinco & $5,3 \mathrm{mg}$ & $0,73 \mathrm{mg}$ \\
\hline Cobre & $410 \mu \mathrm{g}$ & $57 \mu \mathrm{g}$ \\
\hline Manganês & $0,20 \mathrm{mg}$ & $0,03 \mathrm{mg}$ \\
\hline Molibdênio & $11 \mu \mathrm{g}$ & $1,6 \mu \mathrm{g}$ \\
\hline Selênio & $15 \mu \mathrm{g}$ & $2,0 \mu \mathrm{g}$ \\
\hline Cromo & $11 \mu \mathrm{g}$ & $1,5 \mu \mathrm{g}$ \\
\hline Iodo & $100 \mu \mathrm{g}$ & $14 \mu \mathrm{g}$ \\
\hline Vitamina A & $406 \mu \mathrm{g} R E$ & $56 \mu \mathrm{g} \mathrm{RE}$ \\
\hline Vitamina D & $8,8 \mu \mathrm{g}$ & $1,2 \mu \mathrm{g}$ \\
\hline Vitamina $\mathrm{E}$ & $4,6 \mathrm{mg} \alpha \mathrm{RE}$ & $0,63 \mathrm{mg} \alpha \mathrm{RE}$ \\
\hline Vitamina $\mathrm{K}$ & $42 \mu \mathrm{g}$ & $5,9 \mu \mathrm{g}$ \\
\hline Vitamina B1 & $0,54 \mathrm{mg}$ & $0,07 \mathrm{mg}$ \\
\hline Vitamina B2 & $0,54 \mathrm{mg}$ & $0,07 \mathrm{mg}$ \\
\hline Niacina & $4,9 \mathrm{mg}$ & $0,68 \mathrm{mg}$ \\
\hline Ácido Pantotênico & $2,9 \mathrm{mg}$ & $0,40 \mathrm{mg}$ \\
\hline Vitamina B6 & $0,54 \mathrm{mg}$ & $0,07 \mathrm{mg}$ \\
\hline Ácido Fólico & $64 \mu \mathrm{g}$ & $8,8 \mu \mathrm{g}$ \\
\hline Vitamina B12 & $1,3 \mu \mathrm{g}$ & $0,18 \mu \mathrm{g}$ \\
\hline Biotina & $19 \mu \mathrm{g}$ & $2,6 \mu \mathrm{g}$ \\
\hline Vitamina $\mathrm{C}$ & $52 \mathrm{mg}$ & $7,1 \mathrm{mg}$ \\
\hline Colina & $95 \mathrm{mg}$ & $13 \mathrm{mg}$ \\
\hline Inositol & $108 \mathrm{mg}$ & $15 \mathrm{mg}$ \\
\hline Taurina & $30 \mathrm{mg}$ & $4,1 \mathrm{mg}$ \\
\hline L-carnitina & $9,5 \mathrm{mg}$ & $1,3 \mathrm{mg}$ \\
\hline Nucleotídeos: & $24 \mathrm{mg}$ & $3,3 \mathrm{mg}$ \\
\hline Citidina-5-monofosfato & $8,2 \mathrm{mg}$ & $1,1 \mathrm{mg}$ \\
\hline Uridina-5-monofosfato & $5,7 \mathrm{mg}$ & $0,80 \mathrm{mg}$ \\
\hline Adenosina-5-monofosfato & $5,0 \mathrm{mg}$ & $0,70 \mathrm{mg}$ \\
\hline Guanosina-5-monofosfato & $1,7 \mathrm{mg}$ & $0,24 \mathrm{mg}$ \\
\hline Inosina-5-monofosfato & $3,2 \mathrm{mg}$ & $0,45 \mathrm{mg}$ \\
\hline
\end{tabular}

Fonte: Dados nutricionais da Fórmula 1 (2021). 
Research, Society and Development, v. 10, n. 11, e570101119470, 2021

(CC BY 4.0) | ISSN 2525-3409 | DOI: http://dx.doi.org/10.33448/rsd-v10i11.19470

Tabela 6 - Tabela nutricional da Fórmula 2.

\section{Informação Nutricional}

\begin{tabular}{|c|c|c|}
\hline & Quantidade em 100 g de pó & Quantidade em 100ml \\
\hline Valor Energético & $400 \mathrm{kcal}=1680 \mathrm{~kJ}$ & $100 \mathrm{kcal}=420 \mathrm{~kJ}$ \\
\hline Carboidratos & 59g dos quais: & 15g, dos quais: \\
\hline Açúcares & $5,3 \mathrm{~g}$ & $1,8 \mathrm{~g}$ \\
\hline Proteínas & $10 \mathrm{~g}$ & $2,5 \mathrm{~g}$ \\
\hline Gorduras Totais & 14g, das quais: & $3,5 \mathrm{~g}$, das quais: \\
\hline Gorduras Saturadas & $5,3 \mathrm{~g}$ & $1,3 \mathrm{~g}$ \\
\hline Gorduras trans & $0 g$ & $0 g$ \\
\hline Gorduras monoinsaturadas & $6,1 \mathrm{~g}$ & $1,5 \mathrm{~g}$ \\
\hline Gorduras poli-insaturadas & $1,9 \mathrm{~g}$ & $0,5 \mathrm{~g}$ \\
\hline Ômega 6 & $1,5 \mathrm{~g}$ & $0,4 \mathrm{~g}$ \\
\hline Ômega 3 & $0,4 \mathrm{~g}$ & $0,1 \mathrm{~g}$ \\
\hline Colesterol & $0 \mathrm{mg}$ & $0 \mathrm{mg}$ \\
\hline Fibra Alimentar & $0 \mathrm{~g}$ & $0 \mathrm{~g}$ \\
\hline Sódio & $240 \mathrm{mg}$ & $60 \mathrm{mg}$ \\
\hline Potássio & $468 \mathrm{mg}$ & $117 \mathrm{mg}$ \\
\hline Cloro & $368 \mathrm{mg}$ & $92 \mathrm{mg}$ \\
\hline Cálcio & $200 \mathrm{mg}$ & $50 \mathrm{mg}$ \\
\hline Fósforo & $155 \mathrm{mg}$ & $39 \mathrm{mg}$ \\
\hline Magnésio & $50 \mathrm{mg}$ & $13 \mathrm{mg}$ \\
\hline Ferro & $2,5 \mathrm{mg}$ & $0,62 \mathrm{mg}$ \\
\hline Zinco & $2,0 \mathrm{mg}$ & $0,50 \mathrm{mg}$ \\
\hline Cobre & $240 \mu \mathrm{g}$ & $60 \mu \mathrm{g}$ \\
\hline Manganês & $0,20 \mathrm{mg}$ & $0,05 \mathrm{mg}$ \\
\hline Molibdênio & $14 \mu \mathrm{g}$ & $3,5 \mu \mathrm{g}$ \\
\hline Selênio & $10 \mu g$ & $2,5 \mu \mathrm{g}$ \\
\hline Cromo & $5,0 \mu \mathrm{g}$ & $1,9 \mu \mathrm{g}$ \\
\hline Iodo & $28 \mu \mathrm{g}$ & $7,0 \mu \mathrm{g}$ \\
\hline Vitamina A & $148 \mu \mathrm{g}-\mathrm{RE}$ & $37 \mu \mathrm{g} \mathrm{RE}$ \\
\hline Vitamina D & $3,2 \mu \mathrm{g}$ & $0,80 \mu \mathrm{g}$ \\
\hline Vitamina E & $2,3 \mathrm{mg}-\alpha-\mathrm{TE}$ & $0,59 \mathrm{mg}-\alpha-\mathrm{RE}$ \\
\hline Vitamina $\mathrm{K}$ & $14 \mu g$ & $3,5 \mu \mathrm{g}$ \\
\hline Vitamina B1 & $0,24 \mathrm{mg}$ & $0,06 \mathrm{mg}$ \\
\hline Vitamina B2 & $0,32 \mathrm{mg}$ & $0,08 \mathrm{mg}$ \\
\hline Niacina & $3,8 \mathrm{mg}$ & $0,95 \mathrm{mg}$ \\
\hline Ácido Pantotênico & $1,0 \mathrm{mg}$ & $0,25 \mathrm{mg}$ \\
\hline Vitamina B6 & $0,32 \mathrm{mg}$ & $0,08 \mathrm{mg}$ \\
\hline Ácido Fólico & $40 \mu \mathrm{g}$ & $10 \mu \mathrm{g}$ \\
\hline
\end{tabular}


Research, Society and Development, v. 10, n. 11, e570101119470, 2021

(CC BY 4.0) | ISSN 2525-3409 | DOI: http://dx.doi.org/10.33448/rsd-v10i11.19470

\begin{tabular}{l|l|l}
\hline Vitamina B12 & $0,28 \mu \mathrm{g}$ & $0,07 \mu \mathrm{g}$ \\
\hline Biotina & $8,0 \mu \mathrm{g}$ & $2,0 \mu \mathrm{g}$ \\
\hline Vitamina C & $13 \mathrm{mg}$ & $3,9 \mathrm{mg}$ \\
\hline Colina & $77 \mathrm{mg}$ & $19 \mathrm{mg}$ \\
\hline Carnitina & $10 \mathrm{mg}$ & $2,5 \mathrm{mg}$ \\
\hline Taurina & $20 \mathrm{mg}$ & $5,0 \mathrm{mg}$ \\
\hline Inositol & $7,6 \mathrm{mg}$ & $1,9 \mathrm{mg}$ \\
\hline
\end{tabular}

Fonte: Dados nutricionais da Fórmula 2 (2021).

A Fórmula 1 apresenta na sua tabela nutricional alguns ácidos que não possui na Fórmula 2, podendo citar o ácido linoleico, ácido alfa-linolênico, ácido docosahexaenóico (DHA) e ácido araquidônico (ARA). Além dos ácidos, a Fórmula 1 apresenta nucleotídeos, ausentes na Fórmula 2. A presença desses ácidos e nucleotídeos pode ser uma explicação para a variação de $\mathrm{pH}$ entre as duas fórmulas, sendo necessário um estudo mais aprofundado para confirmar. É possível notar, também, que as quantidades dos constituintes da Fórmula 2 apresentam valores maiores, quando comparado com a Fórmula 1.

Outro aspecto bastante notório é que depois de 24 horas de preparo, os $\mathrm{pH}$ das duas fórmulas preparadas com água mineral apresentaram um valor relativamente inferior em comparação com o pH das fórmulas preparadas com água filtrada. Vale lembrar que a água mineral não passou pelo processo de fervura, e isso pode ter influência nessa redução.

A RDC no 247 de 2005 descreve a água mineral como a água obtida diretamente de fontes naturais ou por extração de águas subterrâneas. Ela é caracterizada pelo conteúdo definido e constante de sais minerais, oligoelementos e outros constituintes considerando as flutuações naturais.

A água pode servir de veículo para vários agentes biológicos e químicos independente da fonte (superficial ou subterrânea). Segundo Pontara et al. (2011) a água mineral não é totalmente isenta de impurezas podendo ter microrganismos presentes.

A RDC n ${ }^{\circ} 48$ de 2014 preconiza que essas fórmulas devem ser preparadas com água fervida e posteriormente resfriada. Um estudo de análise de risco da OMS (Fao \& Who, 2006) estabeleceu que o risco é acentuadamente reduzido quando as fórmulas são reconstituídas com água fervida, uma vez que o processo de fervura destruirá todos os microrganismos eventualmente presentes.

Como a água mineral não foi fervida e por ter a possibilidade de conter microrganismos, as fórmulas preparadas com essa água, podem ter sido contaminadas, e no decorrer do tempo, houve um aumento no crescimento microbiano. A contaminação microbiana afeta tanto a segurança do usuário quanto a qualidade química e física do produto, pois pode acarretar alteração do pH e da cor (Oliveira; Rossato \& Bertol, 2016). Para confirmar essa hipótese, seria necessária uma análise microbiológica.

Além da água, vale lembrar que essas fórmulas não são um produto estéril, mesmo tendo sido fabricadas de acordo com os padrões de higiene em vigor. Isto significa que ocasionalmente podem conter microrganismos patogénicos ou podem ser contaminadas facilmente (Oms, 2015).

Comparando o $\mathrm{pH}$ das Fórmulas 1 e 2 com o $\mathrm{pH}$ do leite humano, o que mais se aproximou foi o da Fórmula1. Segundo a Rede Brasileira de Bancos de Leite Humano (2011), em seu material Leite Humano Ordenhado, constatou que em condições normais, o leite humano tende a apresentar pH ligeiramente ácido, próximo ao da neutralidade, situando-se entre 6,5 e 6,9.

\section{Conclusão}

No teste de reconstituição das fórmulas, as duas marcas apresentaram-se estáveis após o preparo, nos dois tipos de água, sem a presença de grumos e partículas visíveis a olho nu. Após 24 horas, as duas fórmulas continuaram estáveis e sem nenhum 
precipitado.

No teste de cor, as duas marcas apresentaram a coloração braço-amarelado após o preparo, nos dois tipos de água. No decorrer do tempo, elas continuaram com a mesma coloração inicial, não apresentando alteração no decorrer do tempo.

$\mathrm{Na}$ análise de $\mathrm{pH}$, houve uma diferença entre as duas fórmulas analisadas. A Fórmula 1 apresentou-se mais ácida e a Fórmula 2, mais alcalina. Além disso, no decorrer do tempo houve uma pequena redução nos valores de $\mathrm{pH}$ em ambas as fórmulas e nos dois tipos de água.

Dessa forma, conclui-se que as duas Fórmulas infantis à base de aminoácidos livres só apresentaram pequenas variações no quesito de $\mathrm{pH}$. As fórmulas podem ser consumidas até 24 horas, desde que seja armazenado de acordo com a recomendação da legislação vigente, ou seja, mantendo o produto em geladeira em uma temperatura menor que $5^{\circ} \mathrm{C}$.

Como a água mineral não foi fervida e por ter a possibilidade de conter microrganismos, as fórmulas preparadas com essa água, podem ter sido contaminadas, e no decorrer do tempo, houve um aumento no crescimento microbiano.

Consequentemente, é de suma importância a realização do controle físico-químico, pois é uma parte obrigatória no controle sanitário e de qualidade desses produtos, verificando a presença de elementos que possam apresentar riscos à saúde humana. Além disso, é necessário a realização de mais testes físico-químicos para garantir a qualidade dos produtos analisados.

Esse trabalho apresenta importância ao profissional farmacêutico porque esse tipo de fórmula é adquirido apenas em farmácias e muitas vezes o consumidor busca alguma orientação sobre esse produto especificamente.

\section{Referências}

Assunção, R. M. A. 2008. Enterobacter sakazakii em fórmulas lácteas infantis em pó: implementação da metodologia de detecção e avaliação microbiológica de amostras comercializadas no distrito de lisboa. Dissertação (mestrado em Medicina Veterinária) - Faculdade de Medicina Veterinária da Universidade Técnica de Lisboa, Lisboa.

Alves, J. Q. N.; Mendes, J. F. R.; Jaborandy, M. de L. (2017). Perfil nutricional e consumo dietético de crianças alérgicas à proteína do leite de vaca acompanhadas em um hospital infantil de Brasília/DF, Brasil. Comunicação em Ciências da Saúde, Brasília, v. 28, n. 3/4, p.402-412.

Brasil. (2018). Ministério da Saúde. Comissão Nacional de Incorporação de Tecnologia no SUS. Fórmulas nutricionais para crianças com alergia à proteína do leite de vaca. Brasília: Ministério da Saúde.

Brasil. (2017). Ministério da Saúde. Comissão Nacional de Incorporação de Tecnologia no SUS. Protocolo Clínico e Diretrizes Terapêuticas Alergia à Proteína do Leite de Vaca (APLV). Brasília: Ministério da Saúde.

Britto, K. B. (2014). Análise da qualidade de bebidas lácteas achocolatadas comercializadas em Teresina-PI. Trabalho de Conclusão de Curso (Bacharelado em Farmácia) - Faculdade Integral Diferencial, Teresina.

Fao/Who. (2006). Enterobacter sakazakii and Salmonella in powdered infant formula. Meeting Report. Joint Fao/Who Technical Meeting on Enterobacter sakazakii and Salmonella Powdered Infant Fórmula, Rome, Italy, 16-20 January.

Ferreira, S. et al. (2014). Alergia às proteínas do leite de vaca com manifestações gastrointestinais. Nascer e Crescer, Porto, v. 23 , n. 2, p.72-79.

Franco, B.D.G.M.\& Landgraf, M. (2008). Microbiologia dos alimentos. São Paulo: Atheneu.

Brasil. (2014). Resolução da Diretoria Colegiada - RDC no 48, de 25 de setembro de 2014. Altera a Resolução da Diretoria Colegiada - RDC no 45, de 25 de setembro de 2014, que dispõe sobre o regulamento técnico para fórmulas infantis para lactentes destinadas a necessidades dietoterápicas específicas e fórmulas infantis de seguimento para lactentes e crianças de primeira infância destinadas a necessidades dietoterápicas específicas. Diário Oficial da União. Brasília.

Oliveira, L. S.; Rossato, L. G. \& Bertol, C. D. (2016). Análise da contaminação microbiológica de diferentes dentifrícios. Revista Odontol UNESP, Araraquara, v. 45, n.2, p.85-89.

Organização mundial da saúde (OMS). (2015) Preparação, manipulação e conservação de fórmulas desidratadas para lactentes: Manual de boas práticas. Instituto Nacional de Saúde Doutor Ricardo Jorge, Portugal.

Organizaçã o mundial de saúde (OMS). (2016). Guideline Uptades on HIV and infant feeding, 2016: the duration of breastfeeding and support from health services to improve feeding practices among mothers living with HIV. Geneva.

Pontara, A. V.; Oliveira, C. D. D.; Barbosa, A. H.; Santos, R. A.; Pires, R. H \& Martins, C. H G. (2011). Microbiological monitoring of mineral water commercialized in Brazil. Brazilian Journal of Microbiology, v. 42, n. 2, p. 554-559.

Ribeiro, S. C. A.; et al. (2007). Alteração da cor da carne de Mapará (Hypophthalmus edentatus) desidratada osmoticamente e seca. Revista Brasileira de Produtos Agroindustriais, Campina Grande, v.9, n.2, p.125-135.

Rodrigues, V. C. C.; et al. (2019). Riscos microbiológicos de fórmulas para lactentes. Brazilian Journal Food Technol, Campinas, v. 22. 
Research, Society and Development, v. 10, n. 11, e570101119470, 2021

(CC BY 4.0) | ISSN 2525-3409 | DOI: http://dx.doi.org/10.33448/rsd-v10i11.19470

Segalla, A. N. et al. (2015). Importância da cor para aceitabilidade e aproveitamento dos alimentos. Instituto Federal do Triângulo Mineiro, Uberlândia.

Tavares, C. S. C. (2013). Estabilidade físico-química de fórmulas infantis. Dissertação (Mestrado em Gestão de Qualidade e Segurança Alimentar) - Escola Superior de Turismo e Tecnologia do Mar, Peniche. 